\title{
Evaluating the timeliness of reporting in a First Nations communicable diseases program
}

\author{
A Lam ${ }^{1,2 *}, \mathrm{~S} \mathrm{Woods}^{3}, \mathrm{~N}^{\text {Ndubuka }}{ }^{2}$
}

\begin{abstract}
Background: Timely reporting of communicable diseases is necessary to enable a prompt response to mitigate and control outbreaks. This is especially true among First Nations communities due to a number of factors, including unique social determinants of health, which can contribute to rapid disease transmission.
\end{abstract}

Objective: To assess the timeliness of reporting for 12 notifiable communicable diseases in the Northern Inter-Tribal Health Authority, which includes 33 First Nations on-reserve communities in Northern Saskatchewan, Canada, and to assess whether there were differences in reporting times depending on degree of remoteness of community, season or year.

Methods: Data for four sexually transmitted infections (STIs) and eight other communicable diseases were abstracted from the integrated Public Health Information System (iPHIS) between 2008 and 2013 and compared against the targets set for reporting in the Saskatchewan Communicable Disease Control Manual. The reporting time was defined as the duration from client exposure or presentation at clinic to the case notification day at Saskatchewan's Ministry of Health. Communicable diseases were evaluated for proportion of cases reported within recommended time, and mean reporting time. Geographical and reporting data were also recorded to assess variations in reporting time among different northern communities and according to season or year.

Results: A total of 9,767 records were identified for the 12 diseases; all had a 14-day recommended reporting time, with the exception of shigellosis, which had a three-day reporting time. Overall, $93.6 \%$ of the diseases were reported in the recommended reporting time, although there was variability among the diseases. All four of the STIs (chlamydia, gonococcal infections, HIV and syphilis) had over $90 \%$ of cases reported within the 14-day recommended time period. Other communicable diseases reporting times varied from a high of $93.4 \%$ for methicillin-resistant Staphylococcus aureus (MRSA), 91.7\% for lab-confirmed influenza and $89.1 \%$ for streptococcal A-invasive disease to a low of $16.2 \%$ for shigellosis and $12.2 \%$ for pertussis. Salmonellosis and pneumococcal-invasive disease were intermediary with $77.4 \%$ and $72.2 \%$, respectively. Mean reporting times indicated that eight of the 12 diseases $(66.7 \%)$ had reporting times similar to or better than recommended times. There appeared to be a correlation between longer reporting periods and the more northern communities. There were no seasonal variations found but yearly-trend analysis demonstrated an anomalous year in 2011, in which all communicable diseases with the exception of STls experienced a peak in reporting delays.

Conclusion: Overall, communicable disease reporting in this northern health authority program met recommended reporting times, although there were variations according to the disease, the area reporting and the year. Further research is needed to understand these variations in order to inform efforts to strengthen communicable disease surveillance among First Nations communities.

\author{
Affiliations \\ ${ }^{1}$ Canadian Public Health Service, \\ Public Health Agency of Canada, \\ Ottawa, ON (at the time of study) \\ ${ }^{2}$ Northern Inter-Tribal Health \\ Authority, Prince Albert, SK \\ ${ }^{3}$ Prince Albert Grand Council, \\ Prince Albert, SK
}

Correspondence: andrew_lam@ rocketmail.com

Suggested citation: Lam A, Woods S, Ndubuka N. Evaluating the timeliness of reporting in a First nations communicable diseases program. Can Commun Dis Rep. 2017;43(6):133-7. https://doi.org/10.14745/ ccdr.v43i06a03

\section{Introduction}

The purpose of a surveillance system is to monitor events and enable a response from public health and front line clinical care $(1,2)$. In a communicable disease (CD) surveillance system, the timeliness of response to $C D$ events is essential in order to attenuate the spread of a disease and prevent an outbreak occurrence. Timeliness is a key attribute recommended in the evaluation of surveillance systems by both the Centres for Disease Control and Prevention and the World Health Organization (3-5). Many studies have evaluated the timeliness of national CD surveillance systems (6-9); however, limited information from evaluations of regional CD surveillance systems have been published.

It is well-known that Indigenous peoples in Canada have a disproportionate amount of the infectious disease burden $(10,11)$. These higher incidence rates are attributable to social determinants of health such as overcrowding, lack of access to health care services and lower education $(12,13)$; however, to understand and appropriately respond to the burden of infectious diseases, it is important to ensure adequate monitoring of this information. Yet, to our knowledge, very 
little has been published on CD surveillance systems among Indigenous peoples in Canada.

\section{The Northern Inter-Tribal Health Authority}

The Northern Inter-Tribal Health Authority (NITHA) is a regional First Nations health organization that comprises four partners: Meadow Lake Tribal Council; Lac La Ronge Indian Band; Prince Albert Grand Council; and Peter Ballantyne Cree Nation. NITHA's public health unit conducts CD surveillance for over 32,000 Registered Indians among Northern Saskatchewan's 33 First Nations on-reserve communities. These communities are distributed among six Regional Health Authorities across Northern Saskatchewan. The CD program at NITHA reports data and conducts follow-up investigations in adherence to The Public Health Act, 1994, the Saskatchewan Disease Control Amendment Regulations, 2014 and the Saskatchewan Ministry of Health's Communicable Disease Control Manual $(14,15)$. At NITHA, all notifiable CDs, with the exception of tuberculosis, are monitored within the CD program. The higher prevalence of tuberculosis among First Nations communities warranted a separate TB program at NITHA for its investigation.

Clinicians, within communities or off-reserve, collect and submit specimens to the Saskatchewan Disease Control Laboratory (SDCL) for laboratory confirmation of the CD. Laboratory results are sent to the Regional Health Authorities, which send the results to the specific regional health organizations. So if the client is a resident from a community within NITHA's coverage, the results would be sent to NITHA. NITHA is then responsible for connecting with frontline community health staff for client follow-up. NITHA reports both laboratory and follow-up information to Saskatchewan's Population Health Branch using the integrated Public Health Information System (iPHIS).

In light of the disproportionate CD burden among First Nations communities, and the lack of research evaluating regional CD surveillance, the objective of this study was to identify the timeliness of CD reporting by NITHA to Saskatchewan's Population Health Branch and assess whether there were differences in reporting times by remoteness of community, season or year.

\section{Methods}

\section{Data Collection}

Data for sexually transmitted infections (STIs) and other CDs were collected from iPHIS for a six-year time period between January 1, 2008 and December 31, 2013. Twelve diseases had a sufficient number of cases over the six year data collection period for disease-specific analysis in this study. Those twelve diseases included four STIs: Chlamydia trachomatis; gonococcal infections; human immunodeficiency virus (HIV); and syphilis; and eight other CDs: hepatitis C; influenza; methicillin-resistant Staphylococcus aureus (MRSA); pertussis; pneumococcal-invasive disease; salmonellosis; shigellosis; and streptococcal A-invasive disease.

\section{Reporting time}

Line listing data from iPHIS for the CDs under study included two dates for each CD: episode date and diagnosis date for STIs; and episode date and laboratory reported date for the other CDs. Reporting time was defined as the number of days from the episode/encounter in the clinic to the diagnosis/ laboratory-reported date. This interval indicated the duration of time between the client presentation at the health facilities, where the specimen was collected, and the time when the result was reported by NITHA to Saskatchewan's Population Health Branch through iPHIS.

\section{Geography and trends over time}

Line listing data from iPHIS included names of 33 First Nations on-reserve communities in Northern Saskatchewan, Canada. The communities were clustered into five councils and geographical areas for analysis: Prince Albert Grand Council; Meadow Lake Tribal Council; Peter Ballantyne Cree Nation; Lac La Ronge Indian Band; and the most northern NITHA communities. Trends over time by season and year were assessed by assigning the season or year of the case by the episode/encounter date.

\section{Statistical analysis}

The comparator to assess the reporting time was the Saskatchewan CD Control Manual recommended time limit for each of the $12 \mathrm{CDs}$ (16); all had a 14-day recommended reporting time, with the exception of shigellosis that had a three day reporting time. Timeliness was analyzed by calculating: a) the proportion of cases that were reported within the recommended time limit; and b) the mean reporting time between the two dates. Confidence intervals with an alpha of 0.05 were calculated, where available. Analyses were performed using Microsoft Office Excel 2010 and statistical software R (17). Only diseases that had more than 30 cases during the observed time period were included in the disease-specific analyses. Yearly reporting time trend analyses were conducted for the total group of STIs and other CDs to account for sample size limitations of individual disease analyses.

\section{Results}

Among the twelve diseases, a total of 9,767 records were identified and $93.6 \%$ of the diseases were reported in the recommended reporting time (Table 1). C. trachomatis, MRSA, and gonococcal infections were the most prevalent diseases, constituting $51.1 \%, 23.2 \%$ and $16.8 \%$ of the identified cases respectively. All STIs (chlamydia, gonococcal infections, HIV and syphilis) had over $90 \%$ of cases reported within the recommended time period; $C$. trachomatis was reported on time for $96.9 \%$ of cases, HIV for $97.5 \%$ of cases, gonococcal infections for $95.8 \%$ of cases and syphilis for $90.7 \%$ of cases. MRSA and lab-confirmed influenza also had a high proportion of cases reported on time: $93.4 \%$ and $91.7 \%$, respectively. The two CDs with the lowest proportion of cases reported on time were pertussis, at $12.2 \%$, and shigellosis, at $16.2 \%$ (shigellosis was the only $C D$ with a recommended three day reporting period). 
The remaining CDs were reported on time for $70-90 \%$ of cases; these included hepatitis $C$, pneumococcal-invasive disease, salmonellosis and streptococcal A-invasive disease.

Table 1: Number and percent of common communicable diseases from the Northern Inter-Tribal Health Authority reported within the recommended time, 2008-2013 ${ }^{1}$

\begin{tabular}{|c|c|c|c|}
\hline $\begin{array}{l}\text { Type of } \\
\text { infection }\end{array}$ & $\begin{array}{l}\text { Name of } \\
\text { infection }\end{array}$ & $\begin{array}{l}\text { Number } \\
\text { of records } \\
\text { (\% of } \\
\text { total) }\end{array}$ & $\begin{array}{l}\text { Number } \\
\text { within the } \\
\text { recommended } \\
\text { reporting time } \\
(\%)^{1}\end{array}$ \\
\hline \multirow{4}{*}{$\begin{array}{l}\text { Sexually } \\
\text { transmitted } \\
\text { infections }\end{array}$} & $\begin{array}{l}\text { Chlamydia } \\
\text { trachomatis }\end{array}$ & $\begin{array}{r}4,989 \\
(51.1)\end{array}$ & 4,835 (96.9) \\
\hline & $\begin{array}{l}\text { Gonococcal } \\
\text { infections }\end{array}$ & $1,636(16.8)$ & 1,567 (95.8) \\
\hline & HIV & $80(0.8)$ & 78 (97.5) \\
\hline & Syphilis & $43(0.4)$ & 39 (90.7) \\
\hline \multirow{8}{*}{$\begin{array}{l}\text { Other } \\
\text { communicable } \\
\text { diseases }\end{array}$} & Hepatitis C & $262(2.7)$ & 212 (80.9) \\
\hline & $\begin{array}{l}\text { Influenza } \\
\text { (lab-confirmed) }\end{array}$ & $229(2.3)$ & $210(91.7)$ \\
\hline & MRSA & $2,265(23.2)$ & 2,115 (93.4) \\
\hline & Pertussis & $82(0.8)$ & $10(12.2)$ \\
\hline & $\begin{array}{l}\text { Pneumococcal- } \\
\text { invasive disease }\end{array}$ & $36(0.4)$ & $26(72.2)$ \\
\hline & Salmonellosis & $31(0.3)$ & $24(77.4)$ \\
\hline & Shigellosis & $68(0.7)$ & $11(16.2)$ \\
\hline & $\begin{array}{l}\text { Streptococcal } \\
\text { A-invasive }\end{array}$ & $46(0.5)$ & 41 (89.1) \\
\hline Combined & Total & 9,767 & 9,141 (93.6) \\
\hline
\end{tabular}

Abbreviations: HIV, Human Immunodeficiency Virus; MRSA, Methicillin-Resistant Staphylococcus aureus, \%; percent

${ }^{1}$ Recommended reporting time was based on targets noted in the Saskatchewan CD Control Manual-14 days for all CDs with the exception of shigelloisis, which was three reporting days

\section{Mean reporting time}

Most CDs had significantly shorter mean reporting times compared with recommended times (Table 2). Syphilis had the longest mean reporting time of 21.1 days; however, reporting times for syphilis, hepatitis $C$ and pneumococcal-invasive disease were not significantly different from recommended times. Shigellosis was the only disease that had a mean reporting time significantly greater than the recommended time at 13.6 days versus three days. Shigellosis was also the only disease with a median reporting time outside the recommended time (data not shown).
Table 2: Mean reporting time from the Northern Inter-Tribal Health Authority to the Saskatchewan Population Health Branch of common infectious disease, 2008-2013

\begin{tabular}{|l|l|r|}
\hline \multicolumn{1}{|c|}{$\begin{array}{c}\text { Type of } \\
\text { infection }\end{array}$} & \multicolumn{1}{|c|}{ Name of infection } & $\begin{array}{c}\text { Mean reporting time } \\
\text { in days }(95 \% \mathrm{Cl})\end{array}$ \\
\hline $\begin{array}{l}\text { Sexually } \\
\text { transmitted } \\
\text { infections }\end{array}$ & Chlamydia trachomatis & $7.1(6.5,7.6)$ \\
\cline { 2 - 3 } & Gonococcal infections & $7.9(7.1,8.7)$ \\
\cline { 2 - 3 } & HIV & $8.2(7.0,9.4)$ \\
\cline { 2 - 3 } & Syphilis & $21.1(0.7,41.5)$ \\
\hline \multirow{3}{*}{\begin{tabular}{l} 
Other $\begin{array}{c}\text { communicable } \\
\text { diseases }\end{array}$ \\
\cline { 2 - 3 }
\end{tabular}} & Hepatitis C & $15.1(5.9,24.3)$ \\
\cline { 2 - 3 } & Influenza (lab-confirmed) & $7.3(4.8,9.8)$ \\
\cline { 2 - 3 } & MRSA & $5.7(5.2,6.2)$ \\
\cline { 2 - 3 } & Pertussis & $8.5(6.4,10.7)$ \\
\cline { 2 - 3 } & $\begin{array}{l}\text { Pneumococcal invasive } \\
\text { disease }\end{array}$ & $10.6(5.5,15.8)$ \\
\cline { 2 - 3 } & Salmonellosis & $9.9(7.2,12.7)$ \\
\cline { 2 - 3 } & Shigellosis & $13.6(9.2,17.9)$ \\
\cline { 2 - 3 } & Streptococcal A-invasive & $6.1(2.9,9.3)$ \\
\hline
\end{tabular}

Abbreviations: $\mathrm{Cl}$, confidence intervals; HIV, Human Immunodeficiency Virus; MRSA, MethicillinResistant Staphylococcus aureus; \%, percent

\section{Trends over time}

The annual mean reporting times of STls and other CDs were evaluated to observe annual trends (Figure 1). STIs had a recommended reporting time of 14 days, and were consistently reported to the Saskatchewan Population Health Branch in fewer than 10 days. Between 2008 and 2013, there was a downward trend in reporting timeliness for STls. The reporting of other CDs was within the recommended time, with the exception of the year 2011, when cases took an average 11.7-15.2 days ( $95 \%$ confidence interval) to be reported. The overall trends for both groups of other CDs and of all CDs combined were downward sloping between 2008 and 2013, as was seen with STIs.

Figure 1: Mean reporting times for different communicable diseases between 2008 and 2013

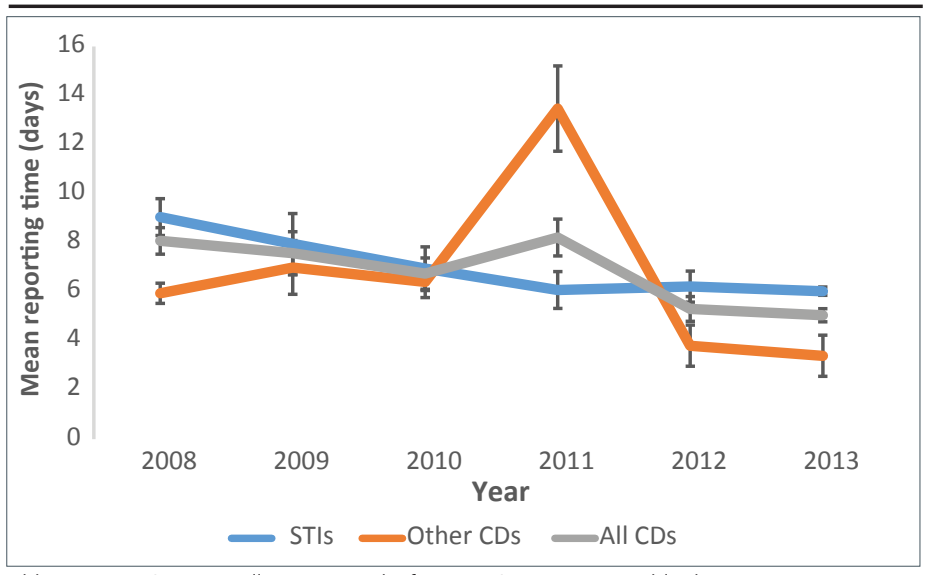

Abbreviations: STIs, sexually-transmitted infections; CDs, communicable diseases Figure note: Error bars depicting a $95 \%$ confidence interval are shown 
Data for STIs and other CDs from each of the four seasons were analyzed to observe seasonal trends. There were no differences of mean reporting times between or within any group of CDs throughout the four seasons (Figure 2).

Figure 2: Mean reporting times for different communicable diseases during the different seasons

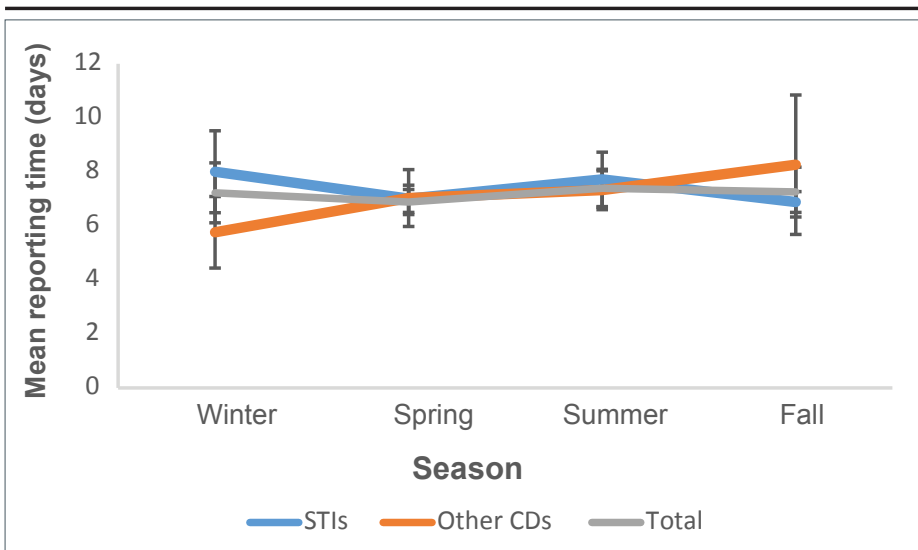

Abbreviations: STIs, sexually-transmitted infections; CDs, communicable diseases Figure note: Error bars depicting a $95 \%$ confidence interval are shown

Mean reporting times for communities and councils were also evaluated from collected data. Mean reporting times were significantly less for Meadow Lake Tribal Council and Peter Ballantyne Cree Nation compared with the northernmost communities. Reporting times from Lac La Ronge Indian Band and Prince Albert Grand Council did not differ between the other communities (data not shown). Data suggests longer reporting times were associated with remoteness of the communities.

\section{Discussion}

Based on almost 10,000 records from First Nations communities over a six-year period, NITHA was successful in reporting $93.6 \%$ of common CDs within the recommended reporting time, although there was some variation among the different diseases. Pertussis and shigellosis were reported least frequently within the recommended time. Pertussis and shigellosis may have had delayed reporting due to clusters and outbreaks of these two diseases, which strained public health resources and prolonged reporting (18). The relatively small number of records for these two diseases also implies that a delay of a few cases can drastically reduce the proportion of timely reported incidents. There was no significant seasonal variation and reporting times were generally getting shorter over the time period of the study. One exception to this was the increased reporting times seen in 2011. This occurred at the time of a shigellosis outbreak, which may have strained public health capacity and created an overall delay in the CD program (19). In terms of geographical analysis, the northernmost communities had slightly longer reporting periods than those communities closer to Regina, Saskatchewan.

This study reports on one of the first evaluations of CD surveillance programs for First Nations communities recently published in the scientific literature. In addition, this was one of the first studies that analyzed both mean and median reporting times, while other studies measured only median reporting times $(7,8,20)$. Measurement of both mean and median reporting times for Shigellosis helped to better understand the distribution of reporting times (8).

There are some limitations to the study. First, there were an insufficient number of records for many CDs. This uncontrollable phenomenon prevented meaningful statistical analyses from being conducted, such as evaluating disease-specific yearly trends. Additionally, data collected from iPHIS only displayed two unique dates for most entries. This system limitation prevented evaluation at individual steps of the surveillance program. For instance, other common steps to evaluate would have been time between exposure and diagnosis, time between patient encounter and laboratory confirmation and time between laboratory confirmation and reporting to the appropriate health unit $(5,8)$. Finally, timeliness is just one aspect of evaluation of a surveillance system, and other indicators, such as internal completeness, internal and external validity and usefulness are other aspects that are often assessed (21).

In terms of next steps, this evaluation has shown that CD reporting does vary by disease, year and remoteness of the community. This evaluation does not explain why the variance occurs. Future investigations may help to explain this by analyzing with increased sample sizes or by conducting qualitative studies to understand reporting mechanisms; for example, the current system uses paper reporting forms whereas an electronic system may be beneficial in achieving a more consistent timely reporting rate (6). Finally, cumulative delay distribution graphs may also be valuable for future analyses (7).

\section{Conclusion}

The communicable disease program at NITHA successfully reported $93.6 \%$ of all collected communicable disease cases to the Saskatchewan Population Health Branch in a timely manner, although there were variations according to the disease, year and remoteness. The reporting times for specific diseases, such as shigellosis, syphilis, hepatitis $C$, and pneumococcal-invasive disease, could be improved to consistently achieve timely reporting.

\section{Authors' statement}

ATL - Conceptualization, methodology, analysis, writing original draft, review and editing; SW - Conceptualization, writing - review and editing, and supervision; NN - Writing review and editing, and supervision

The views expressed in this article are the authors' own and not an official position of any affiliated organization.

\section{Conflict of Interest}

None. 


\section{Acknowledgements}

We thank the community staff and Northern Inter-Tribal Health Authority employees who have helped in collecting and reporting this data.

\section{Funding}

This work was supported by the Public Health Agency of Canada and the Northern Inter-Tribal Health Authority.

\section{References}

1. Jamison D, Breman J, Measham A. Public Health Surveillance: A Tool for Targeting and Monitoring Interventions. In: Disease control priorities in developing countries. Washington (DC): World Bank. 2006;995-1016.

2. Declich S, Carter AO. Public health surveillance: Historical origins, methods and evaluation. Bull World Health Organ. 1994;72(2):285-304. PubMed (https://www.ncbi.nlm.nih. gov/entrez/query.fcgi?cmd=Retrieve\&db=PubMed\&lis t_uids $=8205649 \& d o p t=$ Abstract) .

3. German RR, Lee LM, Horan JM, et al. Updated guidelines for evaluating public health surveillance systems: Recommendations from the Guidelines Working Group. MMWR Recomm Rep. 2001;50(RR-13):1-35; quiz CE1-7. PubMed (https://www.ncbi.nlm.nih.gov/ entrez/query.fcgi?cmd=Retrieve\&db=PubMed\&list_ uids $=18634202 \&$ dopt $=$ Abstract).

4. World Health Organization. Protocol for the Assessment of National Communicable Disease Surveillance and Response Systems: Guidelines for Assessment Teams [Internet]. 2001. Available from: http://www.who.int/csr/resources/ publications/surveillance/WHO_CDS_CSR_ISR_2001_2_EN/ en/.

5. World Health Organization. Communicable disease surveillance and response systems: Guide to monitoring and evaluating [Internet]. 2006. Available from: http://www.who. int/csr/resources/publications/surveillance/WHO_CDS_EPR_ LYO_2006_2.pdf.

6. Akbari $\mathrm{H}$, Majdzadeh $\mathrm{R}$, Rahimi Foroushani $\mathrm{A}$, et al. Timeliness of malaria surveillance system in Iran. Iran J Public Health. 2013;42(1):39-47. PubMed (https://www.ncbi.nlm. nih.gov/entrez/query.fcgi?cmd=Retrieve\&db=PubMed\&li st_uids=23515191\&dopt=Abstract).

7. Jones G, Le Hello S, Jourdan-da Silva N, et al. The French human Salmonella surveillance system: Evaluation of timeliness of laboratory reporting and factors associated with delays, 2007 to 2011. Euro Surveill. 2014;19(1):110. DOI: http://dx.doi.org/10.2807/1560-7917. ES2014.19.1.20664. PubMed (https://www.ncbi.nlm.nih. gov/entrez/query.fcgi?cmd=Retrieve\&db=PubMed\&lis t_uids=24434174\&dopt=Abstract).

8. Yoo HS, Park O, Park HK, et al. Timeliness of national notifiable diseases surveillance system in Korea: A crosssectional study. BMC Public Health. 2009;9:93. DOI: http:// dx.doi.org/10.1186/1471-2458-9-93. PubMed (https://www.
ncbi.nlm.nih.gov/entrez/query.fcgi?cmd=Retrieve\&db=PubM ed\&list_uids=19331696\&dopt=Abstract).

9. Yoo HS, Cho SI, Lee JK, et al. A new surveillance indicator identifying optimal timeliness and accuracy: Application to the Korean National Notifiable Disease Surveillance System for 2001-2007. Epidemiol Infect. 2013;141(12):2634-43. DOI : http://dx.doi.org/10.1017/ S0950268812002956. PubMed (https://www.ncbi.nlm.nih. gov/entrez/query.fcgi?cmd=Retrieve\&db=PubMed\&lis t_uids $=24434174 \& d o p t=$ Abstract).

10. Boulos D, Yan P, Schanzer D, et al. Estimates of HIV prevalence and incidence in Canada, 2005. Can Commun Dis Rep. 2006;32(15):165-174. PubMed (https://www.ncbi. $\mathrm{nlm}$.nih.gov/entrez/query.fcgi?cmd=Retrieve \&db=PubMed\&| ist_uids=16897908\&dopt=Abstract).

11. Ofner-Agostini $M$, Simor $A E$, Mulvey $M$, et al. Methicillinresistant Staphylococcus aureus in Canadian Aboriginal people. Infect Control Hosp Epidemiol. 2006;27(2):204-7. DOI: http://dx.doi.org/10.1086/500628. PubMed (https:// www.ncbi.nlm.nih.gov/entrez/query.fcgi?cmd=Retrieve \&db= PubMed\&list_uids=16465642\&dopt=Abstract).

12. Butler-Jones D, Wong T. Infectious diseases, social determinants and the need for intersectoral action. Can Commun Dis Rep [Internet]. 2016;42(Suppl 1):S18-S20. Available from: http://www.phac-aspc.gc.ca/publicat/ccdrrmtc/16vol42/dr-rm42s-1/ar-04-eng.php.

13. Gracey M, King M. Indigenous health part 1: Determinants and disease patterns. Lancet. 2009;374:65-75. DOI: http:// dx.doi.org/10.1016/S0140-6736(09)60914-4. PubMed (https://www.ncbi.nlm.nih.gov/entrez/query.fcgi?cmd=Retrie ve\&db=PubMed\&list_uids=19577695\&dopt=Abstract).

14. Saskatchewan Ministry of Health. The Public Health Act [Internet]. 1994. Available from: http://www.qp.gov.sk.ca/ documents/English/Statutes/Statutes/P37-1.pdf.

15. Saskatchewan Ministry of Health. The Disease Control Amendment Regulations [Internet]. 2014. Available from: http://www.publications.gov.sk.ca/details.cfm? $p=71179$.

16. Saskatchewan Ministry of Health. Communicable Disease Control Manual: Appendix A Reporting and Follow-up Timelines [Internet]. 2012. Available from: https://www. ehealthsask.ca/services/manuals/Documents/AppendixA.pdf.

17. Team RDC. R: A language and environment for statistical computing [Internet]. 2008. Available from: http://www.rproject.org/.

18. Northern Inter Tribal Health Authority. Annual Report 2013 2014.

19. Northern Inter Tribal Health Authority. Annual Report 2011 2012.

20. Jajosky RA, Groseclose SL. Evaluation of reporting timeliness of public health surveillance systems for infectious diseases. BMC Public Health. 2004;4:29. DOI: http://dx.doi. org/10.1186/1471-2458-4-29. PubMed (https://www.ncbi. $\mathrm{nlm}$.nih.gov/entrez/query.fcgi?cmd=Retrieve\&db=PubMed\&| ist_uids=15274746\&dopt=Abstract).

21. European Centre for Disease Prevention and Control. Data quality monitoring and surveillance system evaluation - A handbook of methods and applications. Stockholm: ECDC; 2014. 